\title{
SAR Processing of Radar Echo Sounder Data
}

\author{
C. Leuschen, S. Gogineni, D. Tammana \\ The University of Kansas, Radar Systems and Remote Sensing Laboratory \\ 2291 Irving Hill Road, Lawrence, Kansas 66045, USA \\ Telephone:785/864-7734 Facsimile:785/864-7789 email: gogineni@rsl.ukans.edu
}

\begin{abstract}
In 1991, NASA initiated a research program for testing airborne laser and radar altimeters for measuring surface elevation of the Greenland ice sheet in conjunction with a coordinated set of surface measurements for validating and interpreting satellite data sets. In 1993, the airborne program was expanded to include the University of Kansas airborne radio echo sounder for acquiring ice thickness along with laser elevation measurements. We have collected a large volume of data with our radio echo sounder and supplied these data to the glaciological community worldwide, and we improved the digital system for collecting coherent data for further processing. We developed a SAR processing algorithm based on the f-k migration technique and used this algorithm to process a subset of data collected over the 2000$\mathrm{m}$ contour line and several outlet glaciers. The results show a 4-10 dB improvement in signal-to-noise ratio and improved along-track resolution. In this paper we will provide a brief description of the algorithm and results of the processing over selected areas
\end{abstract}

\section{INTRODUCTION}

In 1991, NASA initiated a research program to test airborne laser and radar altimeters for measuring surface elevation of the Greenland ice sheet in conjunction with a surface program to validate airborne data and for interpreting satellite microwave data sets. Initial results from these airborne laser measurements showed that surface elevations could be determined to an accuracy of about $20 \mathrm{~cm}[1,2]$. In 1993, the airborne program was expanded to include an airborne radio echo sounder operated by The University of Kansas for determining ice thickness along with laser surface elevations. We have collected ice thickness data along several flight lines with an airborne coherent radar operating at 150 $\mathrm{MHz}$ during the last six years. These radar data are tagged with the Global Positioning System (GPS) for accurate location. We have reduced the data from all missions and supplied these data to others [3-6].

We developed a SAR processing algorithm based on the $\mathrm{f}-\mathrm{k}$ migration technique for extracting ice thickness data in areas with weak bottom echoes and improving along-track resolution. We applied this algorithm to data collected over a 2000-m contour line in the southwestern part of the ice sheet and several outlet glaciers. The SAR processing algorithm improved the signal-to-noise ratio between 4-10 dB and improved along-track resolution by a factor of four or more. In this paper we present a brief description of the system used for collecting data, the SAR processing algorithm theory, and sample results from a few selected outlet glaciers and the 2000-m contour line.

\section{SYSTEM}

The radar system operates at the center frequency of 150 MHz. The transmitter generates a pulse of $1.6 \mu$ s duration and $200 \mathrm{~W}$ peak power (actual transmit power is about $70 \mathrm{~W}$ because of cable losses), which is frequency-modulated over a bandwidth of $17 \mathrm{MHz}$. It uses two antennas that are mounted under the left and right wings of the aircraft: one for transmission and the other for reception. Each antenna is a four-element dipole array with two-way beamwidths of 18 and 66 degrees in planes perpendicular and parallel to the flight path, respectively. The receiver amplifies and compresses the received signals in a weighted Surface Acoustic Wave (SAW) compressor to about an effective pulse of $60 \mathrm{~ns}$. This results in a depth resolution of about $5 \mathrm{~m}$ in ice. The compressed signal is coherently detected and integrated by summing consecutive pulses. The coherent integration serves as a low-pass filter and reduces the alongtrack antenna beamwidth from about 66 degrees to 17 degrees. We believe that the pulse compression and coherent processing are the features that made this system unique and succeeded in sounding outlet glaciers.

After completing the 1993 experiments we determined that the old system was not performing as well as it should and decided to rebuilt the system. We have developed two radar systems: one with connectorized components and the other with RF Integrated Circuits (RFICs). Both these systems have been used for data collection over the Greenland ice sheet since 1996. The transmitter and receiver prototypes of the system using RFICs were developed by undergraduate students as part of a senior design course. Based on these prototypes, a Doctor of Engineering student developed the operational version of the system [7]. In addition we developed a digital system using 12-bit A/D converters also designed to handle higher data rates than possible with the previous system, and to store amplitude and phase data for further processing [8]. 


\section{THEORY}

For the monostatic configuration, wave migration can be explained as a back-propagation of the measured fields that were collected in the air to the reflectors within the ice. Using the exploding reflector model [9], the migrated image, $s(x, z)$, is defined as the value of this back-propagated field, $u(x, z)$, at time equal to zero.

$$
s(x, z)=u(x, z) \|_{t=0}
$$

The fields within the ice are determined by extrapolating the measured data from the image space, $(x, t)$, into the object space, $(x, z)$, using wave theory.

$$
\left.\left.u(x, t)\right|_{z=h} \rightarrow u(x, z)\right|_{t=0}
$$

For FK migration [9,10], this is accomplished by transforming the collected data into the frequency-wavenumber domain and using one-dimensional plane-wave propagation.

$$
U\left(k_{x}, \omega\right)=F_{x t}[u(x, t)]
$$

For a dielectric half space consisting of free space (air) and ice, two sets of wave numbers are defined. By using both the propagation constants for air and ice, any refractions at the air-ice interface are also included.

$$
\begin{aligned}
& \text { Air: } \quad k_{z 0}=\left(k_{0}^{2}-k_{x}^{2}\right)^{1 / 2} \\
& k_{0}=\omega \sqrt{\varepsilon_{0} \mu_{0}} \\
& \text { Ice: } \quad k_{z 1}=\left(k_{i c e}^{2}-k_{x}^{2}\right)^{1 / 2} \\
& k_{\text {ice }}=\omega \sqrt{\varepsilon_{i c e} \mu_{0}}
\end{aligned}
$$

From these wave numbers, two filters are used to propagate the data and construct an image. The first filter, $H_{\text {air }}$, moves the data from the height of the receiver, $\mathrm{z}=\mathrm{h}$, to the air-ice interface, $z=0$. The filter is expressed as a onedimensional back propagation over twice the height of the receiver. The factor of two accounts for the two-way travel time of the EM pulse.

$$
\begin{aligned}
& H_{\text {air }}\left(k_{x}, \omega\right)=\exp \left(j k_{z 0} 2 h\right) \\
& \left.S\left(k_{x}, \omega\right)\right|_{z=0}=H_{\text {air }}\left(k_{x}, \omega\right) U\left(k_{x}, \omega\right)
\end{aligned}
$$

Next, the migrated image at $\mathrm{z}=0$ is determined by converting the field back into the space-time domain and evaluating at time zero.

$$
s(x, z=0)=F_{k \omega}^{-1}\left[S\left(k_{x}, \omega\right)\right]_{t=0}
$$

The second filter, $H_{\Delta}$, moves the fields at $z=0$ to the next depth within the ice, where $d$ is the vertical resolution of the image.

$$
\begin{aligned}
& H_{\Delta}\left(k_{x}, \omega\right)=\exp \left(j k_{z 1} 2 d\right) \\
& \left.S\left(k_{x}, \omega\right)\right|_{z=d}=\left.H_{\Delta}\left(k_{x}, \omega\right) S\left(k_{x}, \omega\right)\right|_{z=0}
\end{aligned}
$$

The fields at subsequent depths are calculated by iteratively applying the filter, while the migrated image at these depths is calculated by using $(8)$ in each iteration.

$$
\left.S\left(k_{x}, \omega\right)\right|_{z=n d}=\left.H_{\Delta}\left(k_{x}, \omega\right) S\left(k_{x}, \omega\right)\right|_{z=(n-1) d}
$$

\section{RESULTS}

Fig. 1 shows sample results with this sytem over a 2000-m contour line in the southwest. These data were collected on July 18, 1998, during the heavy melt period. Ice thickness decreased from about 1700 meters at the beginning of the flight line to about $700 \mathrm{~m}$ at $350 \mathrm{~km}$ from the start with peakto-peak deviations of more than 800 meters. Fig. 2 shows ice thickness data derived from radar data processed with the $\mathrm{f}-\mathrm{k}$ migration technique. The ice thickness in the Jacobshavn Glacier channel is about 2200 meters. We could not observe bottom echoes in the channel before processing. The channel is located in an ablation zone of the ice sheet. These data were collected on June 27, 1998, under significant melt.

\section{CONCLUSIONS}

We developed a modern coherent radar for measuring ice sheet thickness and have collected a large volume of data over the Greenland ice sheet. These data are being combined with other data sets to produce a new thickness map for the Greenland ice sheet. The radar obtains high sensitivity while transmitting low peak power with pulse compression, coherent integration and SAR processing. We used a SAR processing algorithm based on $\mathrm{f}-\mathrm{k}$ migration to improve the signal-to-noise ratio and along-track resolution for obtaining ice thickness in areas with weak bottom echoes and for extracting the bottom echo from clutter caused by off-angle returns and multiple echoes of firn-surface interface.

\section{REFERENCES}

[1] Krabill, W., R. Thomas, C. Martin, R. Swift, and E. Fredrick, "Accuracy of Laser Altimetry over Greenland Ice Sheet," Int. J. Rem Sens., vol 16, no. 7, pp.1211-12222, 1995.

[2] Krabill, W., R. Thomas, K. Jezek, K. Kuivinenm and S. Manizade, "Greenland Ice Sheet Thickness Changes Measured by Laser Atimetry," Geophys. Res. Let., vol. 22, no. 17, pp. 2341-2344, 1995.

[3] Chuah, T.S., S. Gogineni, C. Allen, B. Wohletz, Y.C. Wong, P.Y. Ng, E. Ajayi, "Radar Thickness Measurements over the Southern part of the Greenland Ice Sheet," [1993 data], RSL Technical Report 104702, 1996.

[4] Chuah, T.S., S. Gogineni, C. Allen, B. Wohletz, "Radar Thickness Measurements over the Northern Part of the Greenland Ice Sheet," [1995 data], RSL Technical Report 10470-3, 1996.

[5] Y.C. Wong, S. Gogineni, C. Allen, J. Stiles, J. Legarsky, T. Akins, and K.L. Tee, "Radar Thickness Measurements over the Greenland Ice Sheet: 1997 Results," RSL Technical Report 10470-7, 1998.

[6] Legarsky, J., S.P. Gogineni, C. Allen, T.S. Chuah and Y. C. Wong, "Radar Thickness Measurements over the 
Northern part of Greenland Ice Sheet -- 1996 results," RSL Technical Report 10470-6, March 1997.

[7] Chuah, T.S., "Design and Development of a Coherent Radar Depth Sounder for Measurement of Greenland Ice Sheet Thickness," The University of Kansas, D.E. dissertation, 1-158, 1996.

[8] Akins, T., "Design and Development of an Improved Data Acquisition System for the Coherent Radar Depth
Sounder," Electrical Engineering and Computer Science, The University of Kansas, M.S. Thesis, 1999.

[9] Gazdag, J. and P. Sguazzero, "Migration of Seismic Data," Proceedings of the IEEE, vol. 72, no. 10, pp. 1302- 1315, October 1984.

[10] Stolt, R. H., 1978. "Migration by Fourier Transform," Geophysics, 43: 23-48.

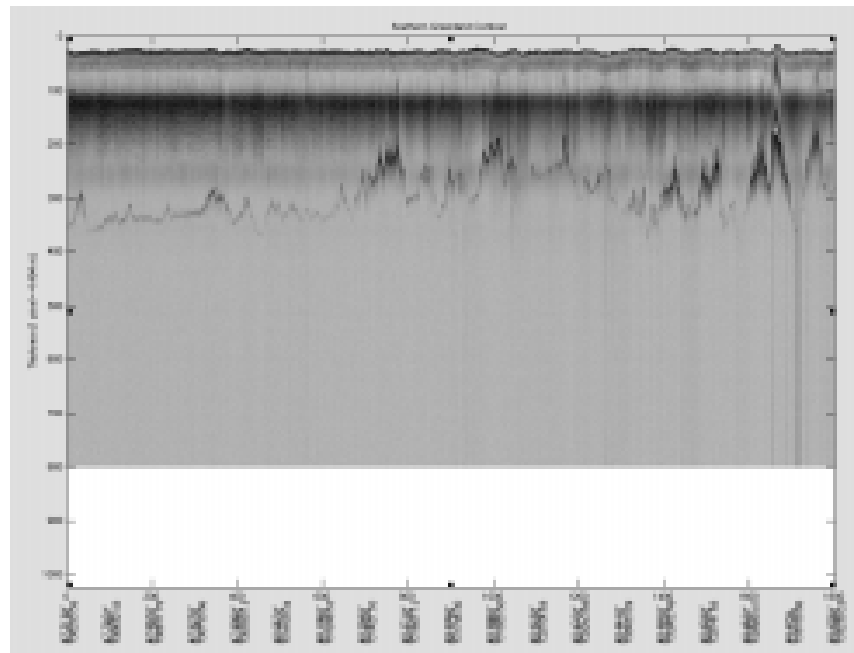

Figure 1: Radar ice thickness data over the 2000-m contour line in the Southwest of the Greenland ice sheet.

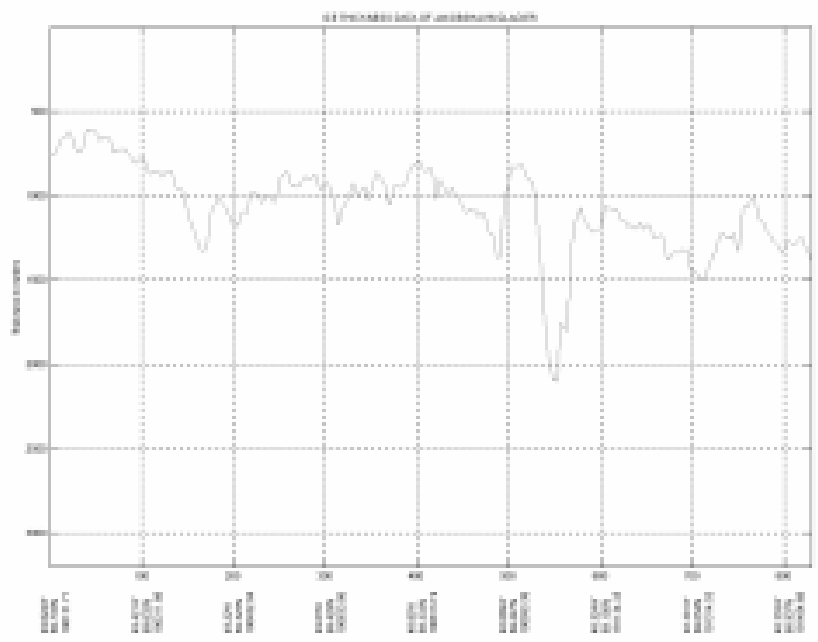

Figure 2: Ice thickness plot over the Jakobshavn region 